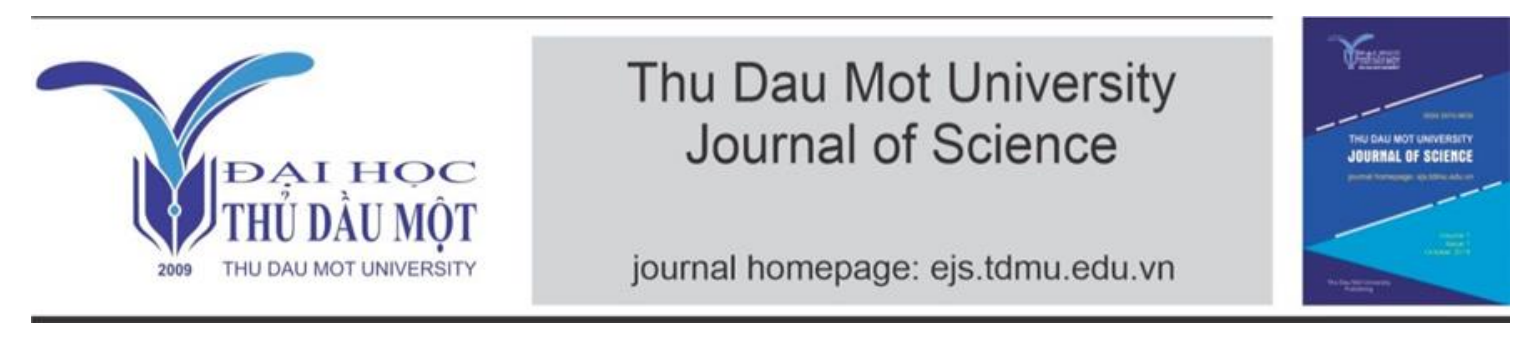

\title{
Assessment of sewage sludge management at Thu Dau Mot wastewater treatment enterprise
}

by Nguyễn Thanh Quang (Thu Dau Mot University)

\author{
Article Info: $\quad$ Received 8 Mar 2021, Accepted 2 Sep 2021, Available online 15 Sep 2021 \\ Corresponding author: quangnt.mt@tdmu.edu.vn \\ https://doi.org/10.37550/tdmu.EJS/2021.03.210
}

\begin{abstract}
Binh Duong province has built and put into operation 29 industrial zones and 10 industrial clusters, contributing to the strong socio-economic development and accompanied by environmental concerns, especially management, waste treatment in general and waste from drainage systems and sanitation works in particular. Thu Dau Mot wastewater treatment enterprise was built including works such as: inlet works, ASBR tank, and disinfection house, sludge concentration tank, sludge extractor, house deodorizing, and so on. The quality of water after treatment meets QCVN 14: 2008 / BTNMT standards (column A), contributing to the protection of Saigon river water sources, ensuring the aesthetics and environmental sanitation of Thu Dau Mot city area. The factory was installed ASBR circulating activated sludge treatment technology, limiting odor generation, not affecting the surrounding environment, increasing $30 \%$ of design capacity compared to traditional SBR tanks of the same volume, easy to operate, low operating costs and saving power. The most common non-toxic organic compounds include materials of plant and animal origin such as proteins, amino acids, sugars, fats; compounds containing $N, P$. Toxic organic compounds include compounds of alkyl phenols, chloro-benzenes. Metals such as: $\mathrm{Zn}, \mathrm{Pb}, \mathrm{Cu}$, $\mathrm{Cd}, \mathrm{Ni}, \mathrm{Cr}, \mathrm{Hg}$, As. Some of these compounds can be toxic to humans and animals. Harmful microorganisms such as pathogenic bacteria, viruses together with parasitic helminthes can increase the potential harm to human, animal and plant health. Inorganic compounds such as silicates, aluminates, and magnesium compounds. After being treated, the sludge will be collected and transported to
\end{abstract}


South Binh Duong Waste Treatment Enterprise to produce construction materials and make compost.

Keywords: sludge, wastewater, organic compounds, inorganic compounds, heavy metals, microorganisms

\section{Introduction}

The sludge is a complex mixture of various impurities, containing many kinds of toxic chemicals. Based on the chemical composition as well as the environmental hazard rate, sludge is divided into various kinds. The sludge contains an energy as much as 10 times of required energy to dispose. On average, drying of sludge wastewater contains lignite energy. More precisely, sludge wastewater contains about 7780 Btu / pound. Therefore, it can use the available energy in sludge wastewater to recover energy from the sludge in the waste into energy, technologies such as biomass gasification. Sludge can be a direct agent causing immediate and long-term environmental pollution. On the other hand, if the sludge is not well managed, it can cause pollution to water sources, causing diseases that affect the ecosystem and public health (Nguyen Viet Anh et al., 2017).

In recent years, a number of legal documents have been issued such as the Law on Environmental Protection 2014 which took effect from January 1, 2015. Environmental standards and regulations on the classification and management of sludge include: QCVN 07: 2009/BTNMT - National technical regulation on hazardous waste thresholds, including regulations applicable to sludge; QCVN 50:2013/BTNMT National technical regulation on hazardous threshold for sludge from water treatment process; TCVN 5298 - 1995: General requirements for the use of wastewater and sludge. Especially in Decree No. 80/2014/ND-CP dated August 6, 2014 of the Government on Sewerage and wastewater treatment, there are a number of detailed regulations on the management of sludge from the drainage system; management of sludge from septic tanks as well as regulations on reuse of sewage sludge. However, there are many missing issues that need to be further researched to improve, which are: Concretize the criteria for selecting wastewater treatment technology; Technical regulations directly related to sludge; Economic and technical norms and norms for collection, transportation and treatment of sludge. Thu Dau Mot wastewater treatment enterprise has applied advanced continuous batch activated sludge biological technology (ASBR); the quality of treated water is grade A, TCVN-14/2008/BTNMT (Do Van Manh et al., 2015). 


\section{Research Methods}

\subsection{Research subjects}

The research on sampling of sludge at Thu Dau Mot wastewater treatment enterprise based on QCVN 50: 2013/BTNMT. National technical regulation on hazard thresholds for sludge from water treatment process and the Circular No. 32/2013/TT-BTNMT national technical regulation on threshold of hazard for sludge to serve as a basis for sludge delimitation and management.

Sampling at least 3 different days, each day's sampling time should be different (beginning, middle and end of a shift or active batch). Must stir, mix well before sampling of sludge; collect at least 03 random representative samples at different positions. The analytical result mean value of the sample is collected to compare with the threshold value of Htc absolute content or the hazard threshold according to Ctc leaching concentration to determine the sludge (Trinh Xuan Lai \& Mai Lien Huong, 2015).

\subsection{Technological process to treat water and sludge at the plant.}

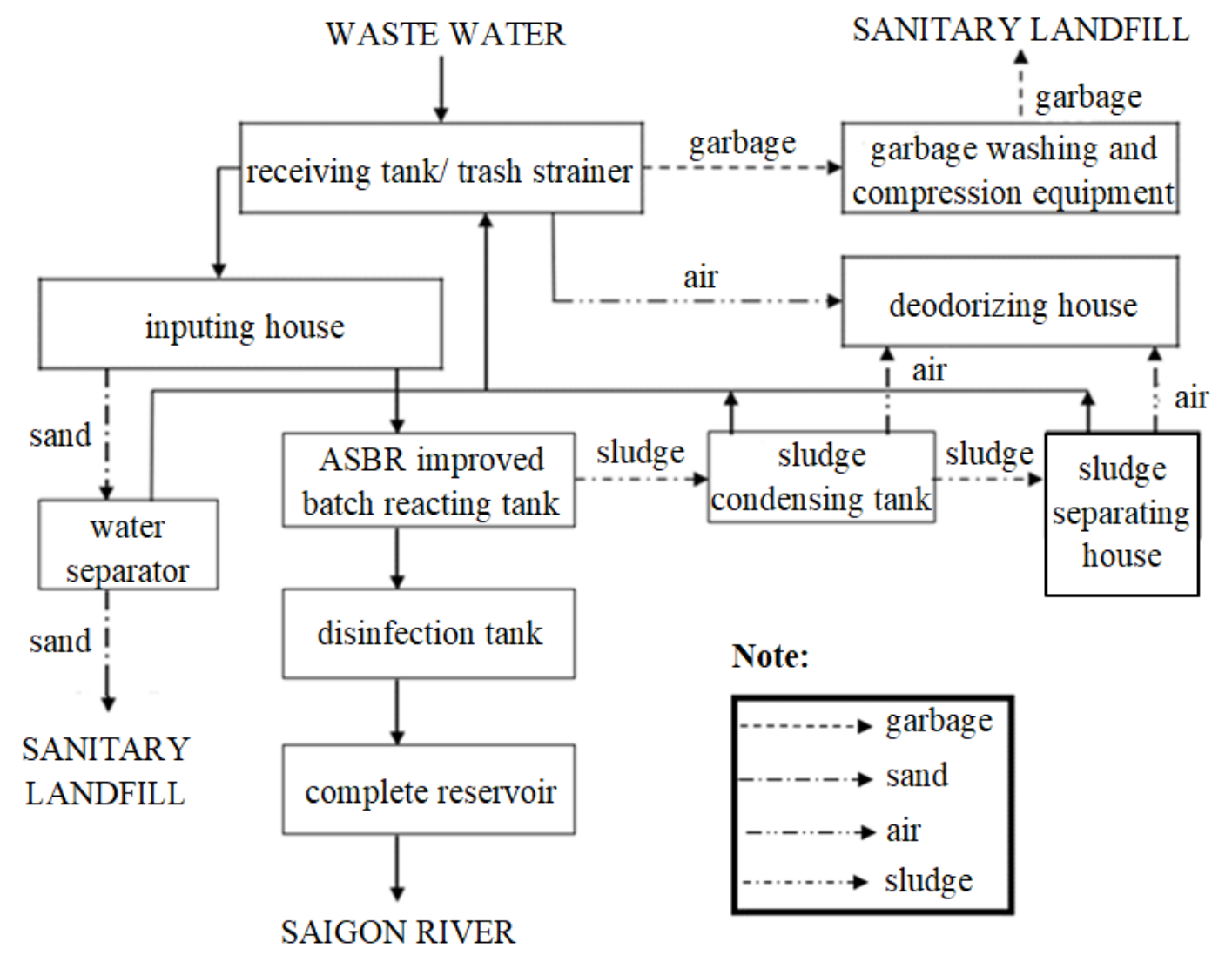

Figure 1. Diagram of technological process for wastewater and sludge treatment at TDM wastewater treatment enterprise 


\section{Discussion results.}

The sludge used for the experiment is taken from Thu Dau Mot wastewater treatment enterprise.

\subsection{Sludge generation process at the plant}

\subsubsection{Operating sludge degester and sludge pumping station}

- Residual sludge from ASBR tank is transported by sludge pump to the sludge degester construction and sludge pumping station through the conveying pipeline DN100. Sludge was put on the distribution board to distribute evenly into 2 sludge degesters. Dilute sludge solution is put into a distribution tank located in the center of the tank, slurry settles and is taken from the bottom of the tank, water is collected by a serrated trough around the perimeter of the tank to return to the treatment area. Sludge degester is installed with a raking system and mechanical stirring to improve the efficiency of water separation as well as the sludge content after compression. 1 gate valve is installed on each pipeline into the sludge degester to isolate the system when it is necessary to maintain or repair the sludge degester.

Operating the sludge raking system.

* Manual mode (MAN)

Turn "AUTO_OF_MAN" switch to "MAN" position, then press "START" button to run the wiper. Press "STOP" button If you want to turn it off.

* Auto run mode (AUTO):

Turn "AUTO_OF_MAN" switch to "AUTO" position and the wiper will run according to PLC system's control from the plant. If turning "AUTO_OF_MAN" switch to "OFF" position, the wiper will not work. The working and fault status of each wiper will be reported to PLC system. "EMERGENCY STOP" (red) press button is used for emergency stop of the system when something goes wrong.

Air compressors \& air dryers

Air compressor and air dryer to supply air to the diaphragm pump to push the sludge to the extractor house. When operating, pay attention to drain the water in the tank while compressing every day to prevent the water in the tank from being mixed into the air.

\section{Diaphragm pumps}

Place the pump as close to the solution to be pumped as possible. Suction pipes and fittings should be place in the minimum distance. Do not reduce the diameter of the suction pipes. For rigidly bonded pipes, a flexible pipe can be installed between the pump and the pipe to reduce vibration and stress on the pipe.

+ Air supply 
The air supply pressure should not exceed 125 PSI. Provide adequate air flow and pressure to the pump. For rigidly bonded pipes, a section of flexible pipe may be used to connect to reduce the stress on the pipe. The weight of the pipe, the pressure regulator, and the air filter shall be supported on suitable supports. Otherwise it will affect the pump. The pressure reducing valve is installed so that the air pressure does not exceed permissible limits.

+ Start the pump

To start the pump, open $1 / 2$ to $3 / 4$ of the air valve. After priming, the air valve can be fully opened to increase the desired air flow. If the valve is opened, the pump cycle increases but the flow does not increase, cavitation pump may be used. The valve is partially closed to get the best effect between air flow and pump rate.

* The sludge condensing tank control panel is linked to the sludge solution separating house control panel. only main equipment such as sludge raking motor, air compressor, and air dryer are kept inside the sludge pump house and sludge storage tank.

\subsubsection{Operating sludge solution separating house}

After being concentrated from the sludge degester, sludge is pumped into 2 sludge compartments at the sludge solution separating house. In the sludge compartment, air is supplied to the sludge tank to avoid settling process in the tank as well as to ensure the same solid concentration in the tank. The air supply system is supplied through 2 air compressors (1 working, 1 backup). Sludge from the centrifugal sludge solution tank works in parallel and sludge is fed from two screw pumps. The flow meter, the turbidity sensor installed from the sludge supply pipeline to the centrifugal sludge solution separator to determine the amount of solids put into the centrifuge to adjust the amount of polymer accordingly. 2 Automatic polymer dispensing systems, automatically dispensing and dosing polymer into the centrifugal sludge solution separator. The polymer system required for sludge centrifugation is $2-6 \mathrm{~kg} /$ ton dry matter depending on each type of sludge.

Sludge from the centrifugal sludge solution separator is transported by the spiral conveyor system to the container for disposal according to regulations. The amount of water separated from the centrifugal sludge solution separator is collected and brought to the input house for re-treatment. Dirty air from the sludge solution separating house is collected and brought the deodorizing house for treatment.

Polymer dosing system

* Mode of operation

To display the process, the system is equipped with KTP 400 control screen. The operator can control via the touch screen with 4 main function keys. Warnings and Error 
alerts are displayed on the screen via text messages and are saved up to 100 messages.

Error alert of the system via horn and lamp. To turn off the horn, press [F4] key on the display screen, then the alert stops, but the cause of the error has not been recovered. After the cause of the error is recovered, press [F4] one more time.

Screw pump (Sludge Pump)

+ Start the pump

Before starting the pump, check to ensure that the pump rotating direction is correct. When operating, should fill the pump with liquid before the first start-up. The operator can control the output flow of the pump via the frequency converter in the control room, avoiding manual adjustment via valve braking on the sludge pipeline. In addition, the operator should pay close attention to the flow of sludge through the flow sensor to turn off the pump when the pump is detected that it is idling for a few seconds.

+ Pause pumping

After stopping the pump, drain off liquid or rinse with water to prevent sedimentation in the pump and the piping and mechanical seals are locked.

Flogwett centrifugal sludge water separator

+ Start the machine

The operator supplies power to the control panel. Wait for the touch screen to finish Loading data, select Auto control mode and let the machine operate automatically. Manual operation of polymer pumps, sludge pumps, and centrifuges may be inaccurate and prevent the machine from extracting sludge. Should have the machine work automatically.

+ Stop the machine

Select STOP in the touch screen. The machine will stop pumping sludge, stop the polymer pump system, and then stop the conveyor system. Wait for the conveyor speed to be around 1500rpm, then open the water valves to clean the machine after finishing operation.

\subsection{Current situation of sludge generation at the plant}

\subsubsection{The amount of sludge generated yearly}

TABLE 1. The table shows the amount of sludge collected over the years

\begin{tabular}{|c|c|c|c|}
\hline Sludge type & In 2017 & In 2018 & In 2019 \\
\hline Fresh sludge $\left(\mathrm{m}^{3}\right)$ & 34,429 & 33,096 & 41,465 \\
\hline Dry sludge $\left(\mathrm{m}^{3}\right)$ & 2,319 & 3,083 & 3,634 \\
\hline
\end{tabular}

(Source: TDM wastewater treatment enterprise) 


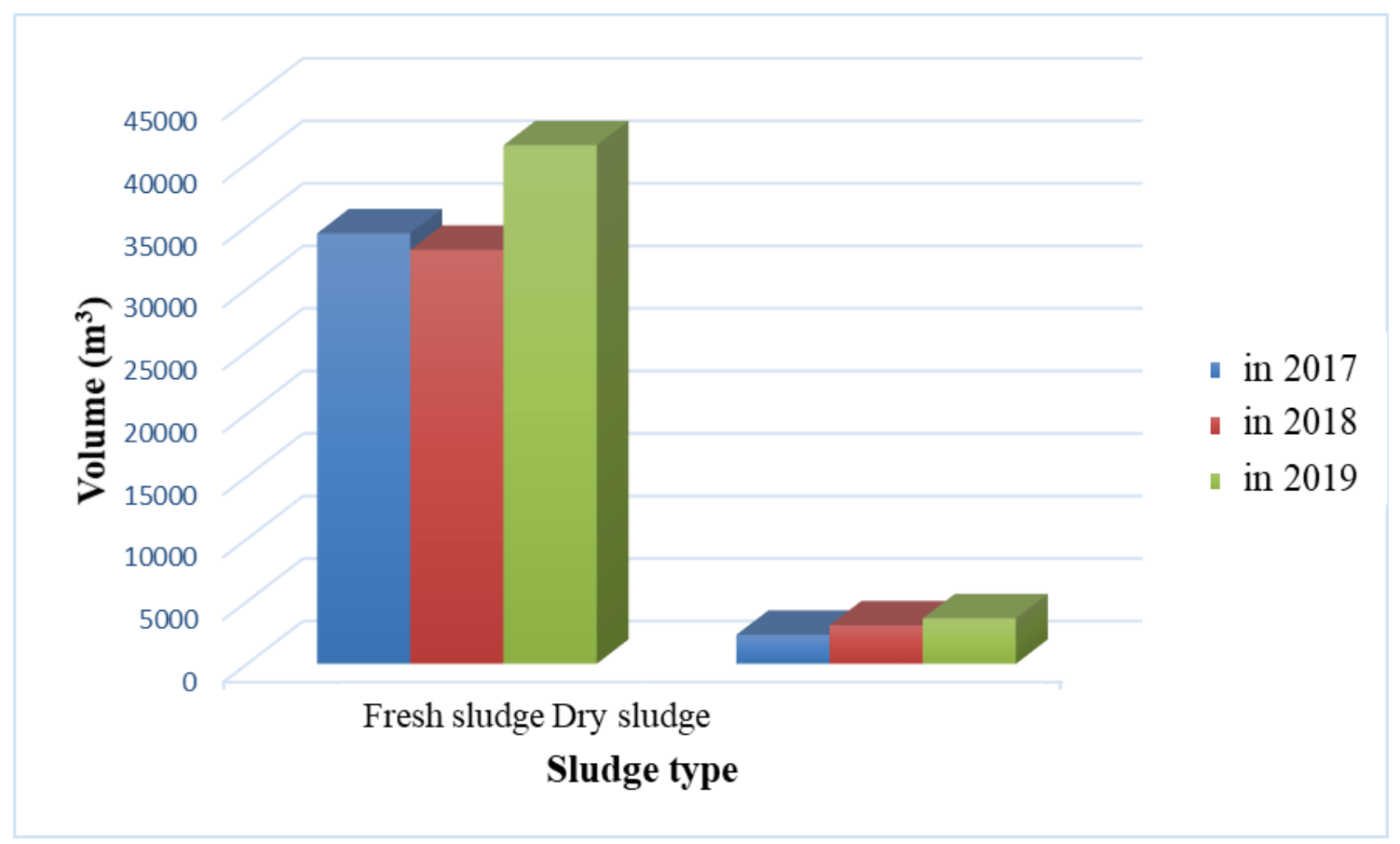

Figure 2. The chart shows the amount of sludge

Based on the chart, it is seen that the amount of sludge generated over the years has increased or decreased slightly, the amount of fresh sludge from 2017 to 2018 is decreased by $1333\left(\mathrm{~m}^{3}\right)$, from 2018 to 2019 increased by $8369\left(\mathrm{~m}^{3}\right)$. The amount of fresh sludge over the years is increased on average by about $3518\left(\mathrm{~m}^{3}\right)$. The amount of dry sludge from 2017 to 2018 is increased by $764\left(\mathrm{~m}^{3}\right)$, from 2018 to 2019 increased by $551\left(\mathrm{~m}^{3}\right)$. The amount of dry sludge per year is increased on average about $657.5\left(\mathrm{~m}^{3}\right)$.

As the insignificant increase in the average water flow input in 3 years and the equivalent composition of the input wastewater source, total amount of discharged final sludge also fluctuates slightly over 3 years.

The amount of sludge generated is quite uniform over the years, it shows that the plant controls the quality of input wastewater and the input water flow is quite good. The sludge treatment process in 3 years has no change, so the amount of sludge generated in 3 years is also relatively stable.

TABLE 2. The amount of sludge cake generated yearly

\begin{tabular}{|c|c|c|c|}
\hline \multirow{2}{*}{ Month } & \multicolumn{3}{|c|}{ The amount of sludge cake generated (tons) } \\
\cline { 2 - 4 } & In 2017 & In 2018 & In 2019 \\
\hline 1 & 216.31 & 314.97 & 322.71 \\
\hline 2 & 261.11 & 364.71 & 346.08 \\
\hline 3 & 173 & 76.79 & 244.87 \\
\hline 4 & 217.43 & 185.73 & 258.18 \\
\hline 5 & 188.91 & 187.43 & 280.37 \\
\hline
\end{tabular}




\begin{tabular}{|c|c|c|c|}
\hline 6 & 45.06 & 326.98 & 339.11 \\
\hline 7 & 139.02 & 236.29 & 362.17 \\
\hline 8 & 201.88 & 343.80 & 289.42 \\
\hline 9 & 277.12 & 231.88 & 324.26 \\
\hline 10 & 265.77 & 168.45 & 273.91 \\
\hline 11 & 252.26 & 306.26 & 314.07 \\
\hline 12 & 151.85 & 339.89 & 279.29 \\
\hline Total & $\mathbf{2 , 3 1 9 . 7 2}$ & $\mathbf{3 , 0 8 3 . 1 8}$ & $\mathbf{3 , 6 3 4 . 4 4}$ \\
\hline
\end{tabular}

(Source: TDM wastewater treatment enterprise)

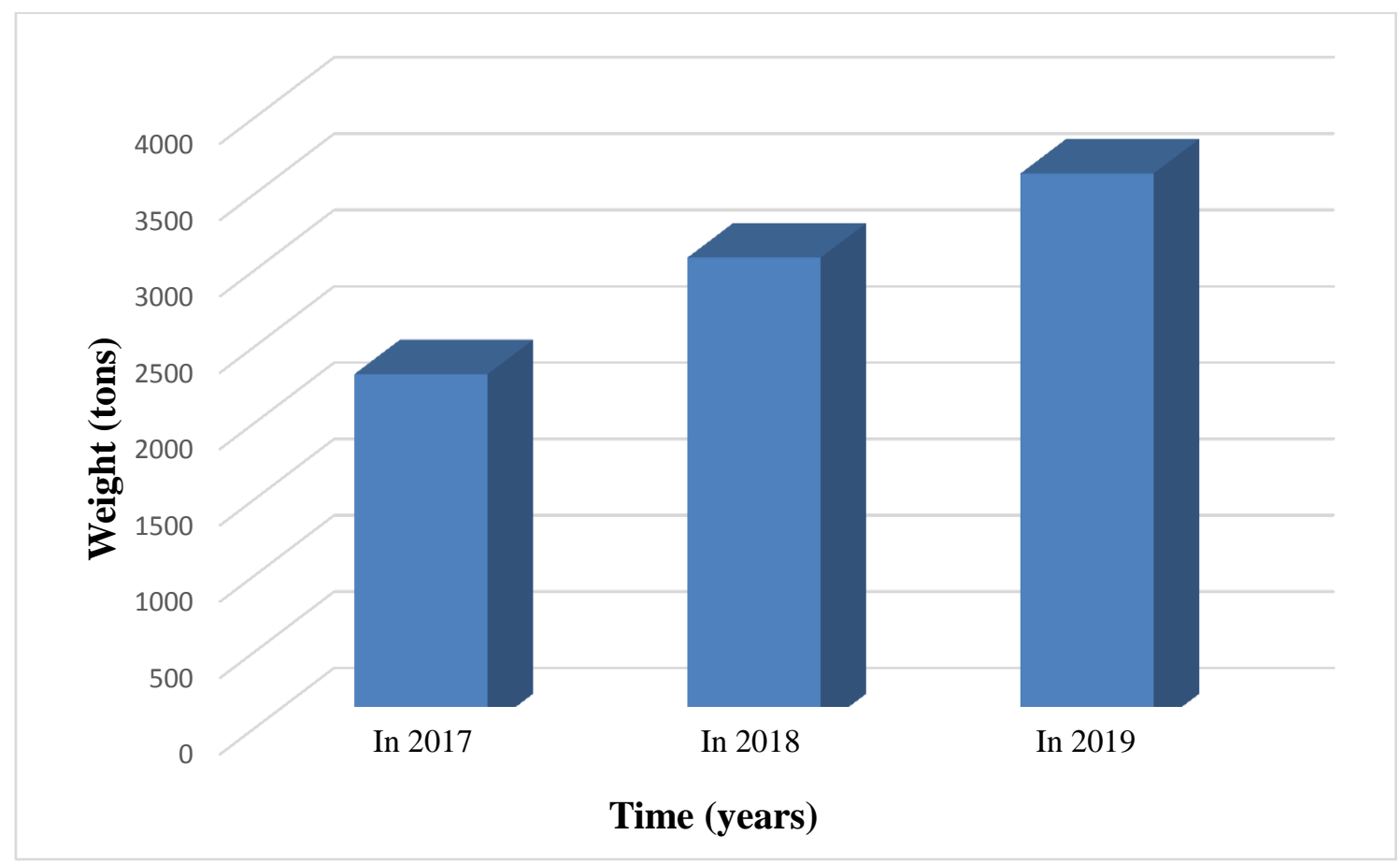

Figure 3. The chart shows total sludge cake generated over the years

The amount of sludge cake from 2017 to 2018 is increased by 763.46 (tons), from 2018 to 2019 increased by 551.262 (tons). The amount of sludge cake per year is increased on average about 657.361 (tons). Total amount of sludge is increased slightly over the years due to the increasing population, the number of people crowding into the inner city areas to live and work is increasing. The demand for water is also increasing, along with the amount of domestic wastewater generated more and more.

Sludge cake is the final amount of sludge from wastewater treatment is discharged into the environment. The amount of sludge cake generated annually of more than 3,000 tons is a relatively large number and tends to increase yearly. If it is not treated in time, it will affect the surrounding environment, especially the pollutants of the sludge seeping into the groundwater and surface water, making the quality of the water deteriorated. 


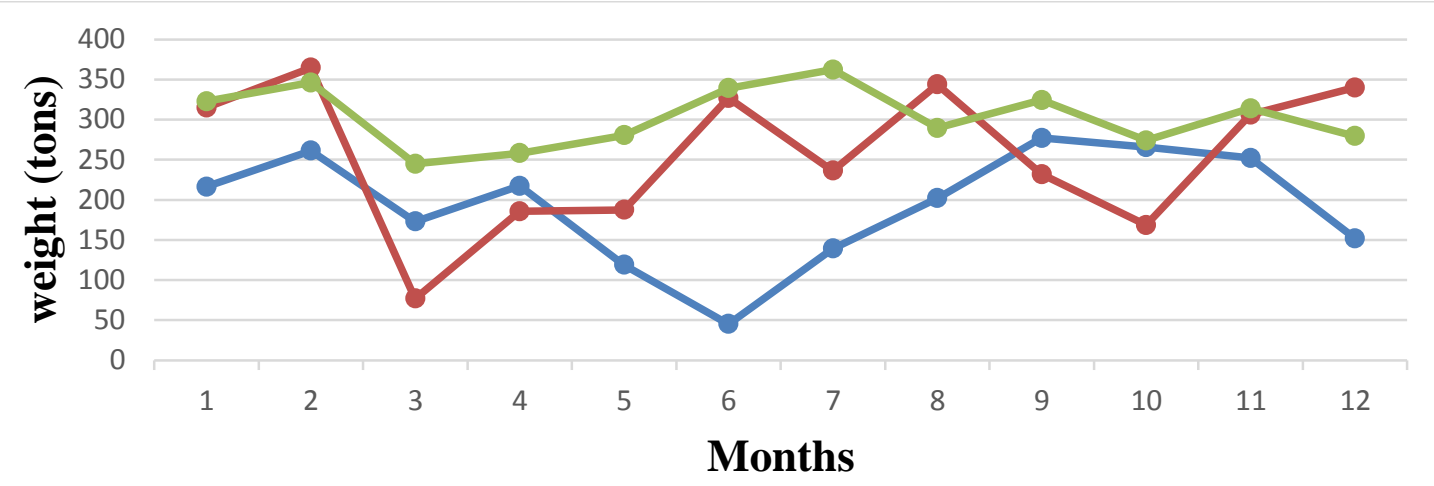

$\longrightarrow$ In $2017 \multimap$ In $2018 \multimap$ In 2019

Figure 4. The chart shows the amount of sludge cake generated by monthly

The amount of sludge cake generated is not stable over the months of the year due to the uneven flow of wastewater into the plant over the months. Amount of sludge generated in January and February is usually higher than the months of the year as people clean their house during the solar new year period results in a lot of sludge in domestic wastewater. There are months when machines are in problem so amount of sludge is less generated.

\subsubsection{Amount of sludge cake is shown by season}

$T A B L E 3$. Amount of sludge cake generated by the season yearly

\begin{tabular}{|c|c|c|c|}
\hline Time & Dry season & Rainy season & Total \\
\hline In 2017 & 949.704 & $1,370.016$ & $2,319.72$ \\
\hline In 2018 & $1,282.09$ & $1,801.09$ & $3,083.18$ \\
\hline In 2019 & $1,451.13$ & $2,183.31$ & $3,634.44$ \\
\hline
\end{tabular}

(Source: TDM wastewater treatment enterprise)

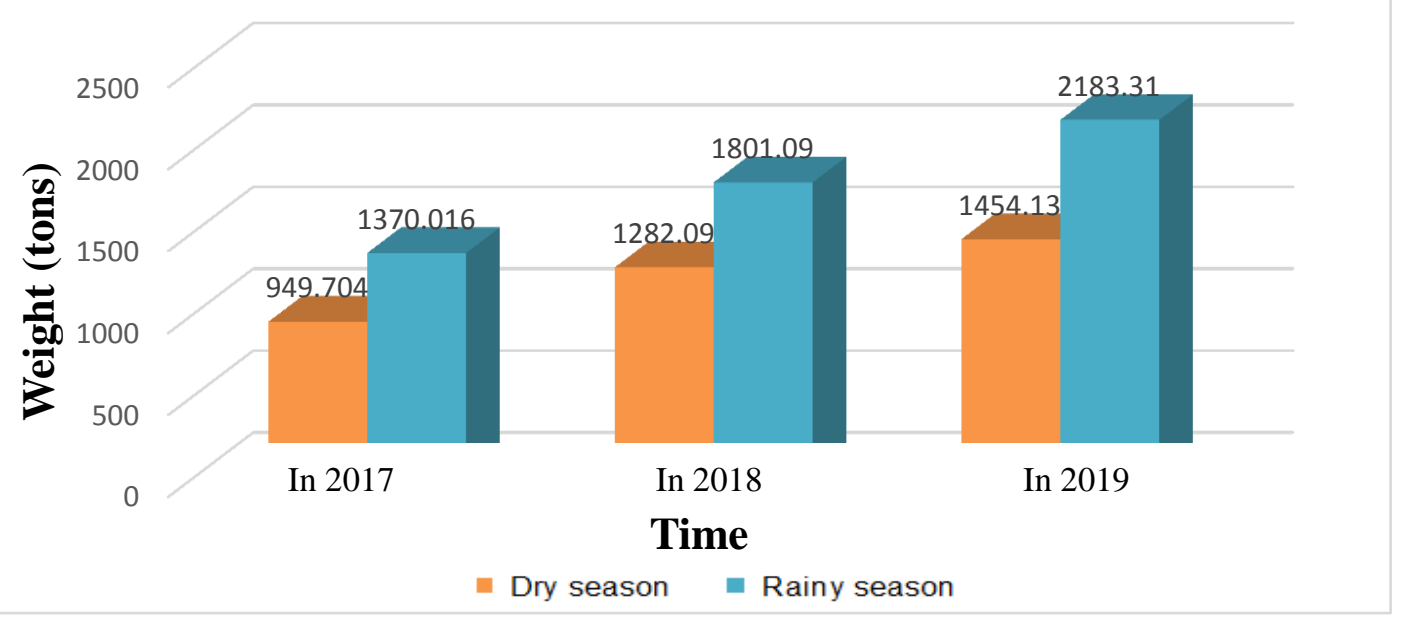

Figure 5. The chart shows the amount of sludge cake by the season 
The chart clearly shows the difference of the amount of sludge cake generated between the rainy season and the dry season. The amount of sludge cake generated in the rainy season is higher than the amount of sludge cake in the dry season about $144 \%$ (420.312 tons) in 2017, about 140\% (519 tons) in 2018 and about 150\% in 2019 (729.18 tons). As the rainfall in the rainy season flows into the domestic wastewater collection system and carries dust and other wastes, therefore, the increased amount of domestic wastewater in the rainy season needs to be treated, resulting in more sludge generation.

The amount of sludge generated in the rainy season is more than the dry season, so it is necessary to build a separate rainwater drainage system to reduce treatment costs and increase wastewater treatment efficiency.

\subsubsection{Assessment of metal content in the sewage sludge}

Heavy metal is considered essential trace elements for plants and animals, it is a toxic when present in concentrations exceeding the using demand. When sewage sludge containing heavy metals is released into the environment, the plants will absorb and they will be contaminated with heavy metals and it can enter into the human body and animals through the digestive tract when humans and animals consume these plants.

Heavy metals can also enter into the human body through the respiratory tract if the atmosphere contains heavy metals. Under the proper conditions, heavy metals in water environment can be released into soil or gaseous environments. Therefore, the disposal of sludge containing heavy metal concentrations in excess of the permitted concentration is very dangerous to humans, animals, plants and the environment.

TABLE 4. Metal content in the sludge through each quarter in 2018

\begin{tabular}{|c|c|c|c|c|c|}
\hline Quarter & As & Pb & Cd & Cu & Zn \\
\hline 1 & 0.02 & 3.91 & 0.015 & 10.75 & 73.75 \\
\hline 2 & $<0.6$ & 2.25 & 0.071 & 6.5 & 24 \\
\hline 3 & 0.15 & 0.4 & $<0.15$ & 1.2 & 3.1 \\
\hline 4 & 0.028 & $<0.05$ & $<0.001$ & 0.55 & 7.0 \\
\hline $\begin{array}{c}\text { QCVN 50:2013/ } \\
\text { BTNMT }\end{array}$ & 2 & 15 & 0.5 & - & 250 \\
\hline
\end{tabular}

(Source: TDM wastewater treatment enterprise)

All metals in the analyzed sludge sample (such as arsenic, lead, cadmium, copper, zinc) meet the output standards and are much smaller than QCVN 50: 2013 / BTNMT. National technical regulation on hazard threshold for sludge from water treatment process.

The sludge has a low metal content, so the beneficial microorganisms in the water treatment process are not affected. When using sludge as a secondary product, there is also no concern about the potential risk of causing environmental pollution and causing human diseases (cancer, damage to the liver, heart, mind, prevent metabolism) 


\subsubsection{Assessment of TSS content in the sewage sludge}

Total suspended solids (TSS) can include sludge, decayed plants and animals, and garbage. High TSS is likely to be a higher concentration of bacteria, nutrients, and heavy metals.

TABLE 5. Amount of TSS (mg/l) in the sewage sludge

\begin{tabular}{|c|c|c|}
\hline Month & $\begin{array}{c}\text { Mixed sludge tank dissociation } \\
\text { solution (mg/l) }\end{array}$ & $\begin{array}{c}\text { Centrifugal water separator dissociation } \\
\text { solution (mg/l) }\end{array}$ \\
\hline 1 & 375 & 690 \\
\hline 2 & 325 & 810 \\
\hline 3 & 267 & 620 \\
\hline 4 & 294 & 650 \\
\hline 5 & 248 & 620 \\
\hline 6 & 235 & 730 \\
\hline 7 & 245 & 910 \\
\hline 8 & 302 & 860 \\
\hline 9 & 268 & 630 \\
\hline 10 & 285 & 860 \\
\hline
\end{tabular}

(Source: TDM wastewater treatment enterprise)

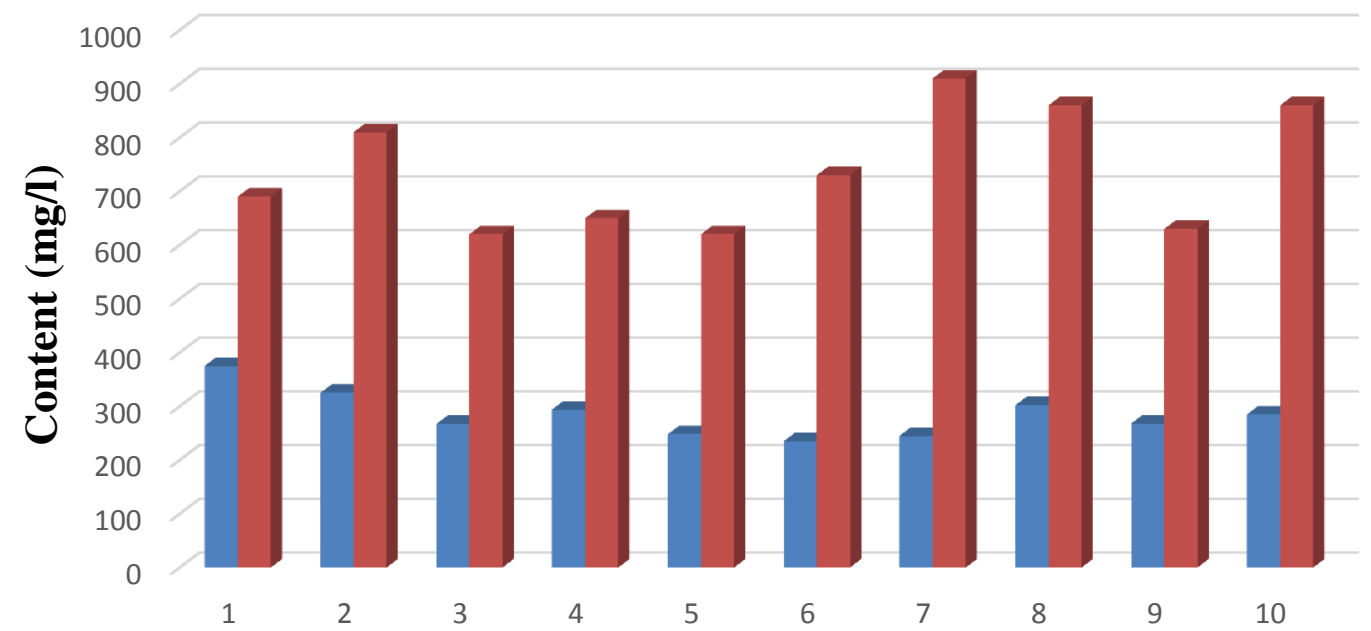

Time (months)

- Mixed sludge tank dissociation solution $\quad$ Centrifugal water separator dissociation solution

Figure 6. The chart shows TSS content over months of the year

TSS content of the mixed sludge tank in the rainy season months is less than the dry season months, so it is found that the sludge of the rainy season is thinner than the dry season. But after the sludge passed through the centrifugal water separator, the amount of TSS remained as high as in the amount of TSS during dry season months.

Based on the chart, it is seen that TSS content at the centrifugal water separator is the 
highest, 2-3 times higher than TSS content of the sludge in the mixed sludge tank. The higher the TSS content is, the higher the ratio of sludge in the solution is.

3.2.5. Assessment of sewage sludge composition in gravity sedimentation tank and centrifugal concentrator

$T A B L E$ 6. Analyzed nutrient content of 2 sludge samples

\begin{tabular}{|l|r|r|}
\hline & Sludge at centrifugal concentrator & \multicolumn{2}{|c|}{$\begin{array}{c}\text { Sludge after the gravity } \\
\text { sedimentation tank }\end{array}$} \\
\hline Moisture $(\%)$ & 23 & 21 \\
\hline $\mathrm{pH}$ & 6.1 & 6.23 \\
\hline$\% \mathrm{TOC}$ & 31.2 & 30.2 \\
\hline$\% \mathrm{~N}$ & 3.0 & 2.6 \\
\hline$\% \mathrm{P}$ & 2.8 & 2.5 \\
\hline $\mathrm{Cu}(\mathrm{mg} / \mathrm{l})$ & 10.75 & 6.5 \\
\hline $\mathrm{Pb}(\mathrm{mg} / \mathrm{l})$ & 3.91 & 2.25 \\
\hline $\mathrm{Cd}(\mathrm{mg} / \mathrm{l})$ & 0.015 & 0.071 \\
\hline $\mathrm{Zn}(\mathrm{mg} / \mathrm{l})$ & 73.75 & 24 \\
\hline
\end{tabular}

(Source: TDM wastewater treatment enterprise)

The analysis results of the sludge sample is showed:

- Sewage sludge contains high organic carbon content (30.3\%-31.2\%).

- Content of nutrients N (2.6\%-3\%), P (2.5-2.8\%) is low.

- Content of heavy metals is low.

The analyzed two sludge samples do not contain hazardous constituents, so they can be used to produce secondary products without potential risks to human health and the environment.

\subsection{Assessment of the sludge operation and management status at the plant}

The Government's Decree No. 80/2014/ND-CP dated August 06th, 2014 on Sewerage and Wastewater Treatment issued some regulations on sludge management as well as regulations on reuse of sewage sludge. The Circular No. 04/2015/TT-BXD dated April $03^{\text {rd }}, 2015$ guiding the implementation of a number of articles of the Decree No. $80 / 2014$ issued quite detailed and concretized regulations on sludge management. This is an important legal document to govern this field. Therefore, the plant has well applied the state management of wastewater treatment and applied modern technology to the management and treatment of sludge effectively in recent years, contributing to important to the environmental protection of Thu Dau Mot City area.

In addition, the plant also applies strict sludge management according to the regulation No. 44/2015/QD-UBND issued the regulations on sludge management in Binh Duong province. 


\subsection{Proposal for co-treatment of sludge and organic waste}

Sewage sludge has low heavy metal content, so it does not affect human health. When sludge is used as secondary products and does not affect organisms or the environment.

Sewage sludge contains high organic carbon content (30.3\%-31.2\%), so it is necessary to find ways to recover this carbon source to create useful by-products such as: Composting, anaerobic, aerobic composting to produce Biogas. However, as the low nutrient content, in order to conduct composting or producing biogas, it is necessary to mix sludge with organic byproducts that are rich in $\mathrm{N}$, $\mathrm{P}$ such as leftovers, organic domestic waste.

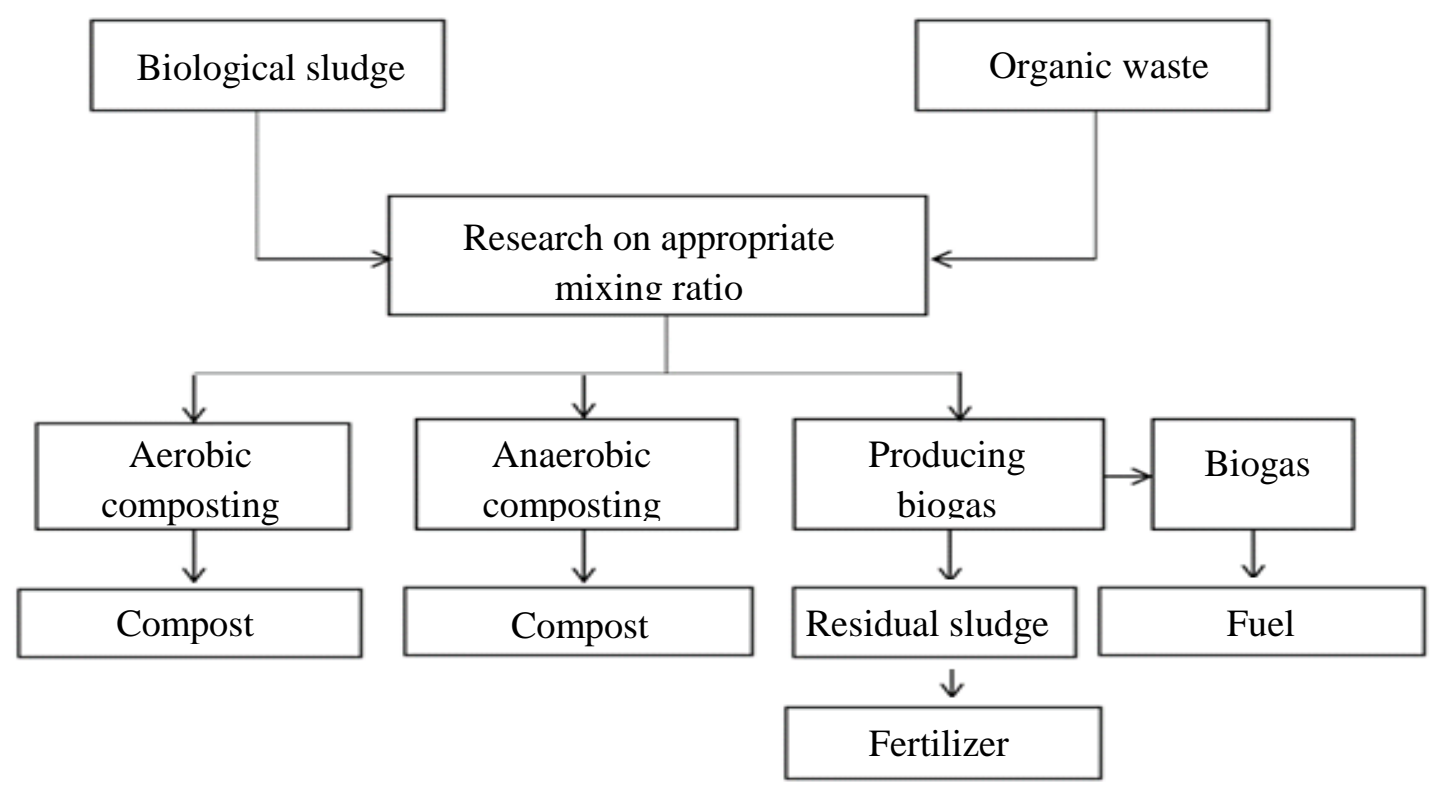

Figure 7. Process of co-treatment of sludge and organic waste

\section{Conclusion}

The speed of urbanization and rapid development of Thu Dau Mot city area is both an opportunity and a challenge for Thu Dau Mot wastewater treatment enterprise. In recent years, the enterprise has performed well the state management, as well as applied modern technology to treat wastewater and sludge effectively.

The results of sludge characterization analysis over the years 2017, 2018, and 2019 at the enterprise show that the sludge here is not harmful, however, if sludge is disposed of at the proper place, but it is disposed in untreated sludge dump, it will pollute the environment due to accumulation of pollutants in the area over time, at the same time, it will cause a lot of danger to future generations. The enterprise has applied advanced continuous batch circulating activated sludge biological technology (ASBR), the quality of the treated water is grade A, TCVN-14/2008/BTNMT. After being treated, the sludge will be 
collected and transported to South Binh Duong Waste Treatment Enterprise to produce construction materials and make compost.

During applying the sludge reuse method, it will help to solve the urgent problem that is the location, the land area of the sludge dump and most importantly, the plan of an effective sludge treatment helps to reduce environmental pollution, in line with the sustainable development strategy. And that the reuse of sludge also brings the enterprise profits.

\section{References}

Do Van Manh, Trinh Van Tuyen, Le Xuan Thanh Thao, Le Minh Tuan, Tran Thi Lien, Nguyen Tuan Minh (2015). Technical sludge pretreatment, anaerobic decomposition, biogas cleaning and power generation. Natural science and technology Publisher.

Hoang Hue (2020). Wastewater treatment. Construction Publisher.

Luong Duc Pham (2012). Wastewater treatment technology by biological methods. Vietnam Education Publisher.

Nguyen Thi Thu Hien, Nguyen Van Phuoc, Tran Minh Huong, Trinh Bao Son (2012). Sludge treatment technology. Ho Chi Minh City National University Publisher.

Nguyen Van Suc (2012). Wastewater treatment technology. Ho Chi Minh City National University Publisher.

Nguyen Viet Anh, Bui Thi Thuy, Vu Thi Minh Thanh (2017). Sludge treatment of wastewater treatment plant. Construction Publisher.

Tran Duc Ha (2006). Urban wastewater treatment. Science and Technology Publisher.

Trinh Le Hung (2009). Wastewater treatment techniques. Education Publisher.

Trinh Xuan Lai (2017). Industrial and Domestic Wastewater Treatment by Technology O/A Design Calculation. Construction Publisher.

Trinh Xuan Lai, Mai Lien Huong (2015). Operating and upgrading design of wastewater treatment facilities using activated sludge method. Construction Publisher. 